\title{
Research on Vulnerability Curve of Waterlogging Disaster for Maize Based on CERES-Maize Model in the Midwest of Jilin Province
}

\author{
Enliang Guo, Jiquan Zhang， Yongfang Wang， Zhenhua Dong
}

School of Environment, Northeast Normal University, Nature Disaster Research Institute, Changchun 130117, China

\section{基于 CERES-Maize 模型的吉林省中西部玉米涝 灾脆弱性曲线研究 \\ 郭恩亮, 张继权, 王永芳, 董振华 \\ 东北师范大学环境学院, 东北师范大学自然灾害研究所, 长春 130117, 中国}

\begin{abstract}
Under the background of global warming, the loss caused by extreme precipitation is becoming more and more serious. As a bridge between risk and disaster losses, at present, research on vulnerability curve has become research focus in the field of disaster risk In this study, based on meteorological data, crop physiological data, and field management data and so on, to select typical waterlogging disaster years as a case, the growth process of Maize in the Midwest of Jilin province was simulated by using the CERES-Maize model of localization and spatial scaling. The disaster intensity index is calculated by copula function, and then builds the construction of waterlogging disaster vulnerability curve of Maize. The results show that: vulnerability curve of waterlogging disaster for maize in descending order are: the emergence - jointing, jointing - heading stage, heading - milk stage, milky - maturity, The results can be used as mitigate water logging disaster for maize growth, choose a reasonable period of irrigation and drainage facilities provide an important basis, in order to achieve the result of optimal Maize planting arrangement.
\end{abstract}

Keywords: The vulnerability of curve; CERES-Maize model; waterlogging disaster; Midwest of Jilin Province
摘要

在全球气候变暖背景下, 极端降水造成的洪涝 灾害损失越来越严重。作为连接风险与灾害损 失的桥梁, 脆弱性曲线的研究已经成为现阶段 灾害风险领域的热点。本研究在收集研究区气 象数据、作物生理数据、田间管理数据等基础 上, 选取典型涝灾年份为案例年, 通过对 CERES-Maize 模型进行本地化和空间升尺度 处理, 对吉林中西部地区玉米生长过程进行逐 日逐网格模拟, 耦合 copula 函数构建的致灾强 度指数进行玉米涝灾脆弱性曲线的构建, 结果 表明: 吉林省中西部地区玉米涝灾脆弱性由大 到小依次为: 出苗一拔节期、拔节一抽雄期、 抽雄一乳熟期、乳熟一成熟期, 研究结果可以 作为减轻涝灾对于玉米生长的影响, 选择合理 的灌溉时期和排水设施提供重要依据, 以达到 玉米种植优化布局的结果。

关键词: 脆弱性曲线; CERES-Maize 模型; 涝灾; 吉林中西部

1. 引言

根据 IPCC 第五次评估报告, 全世界面临 极端气候事件带来的负面影响将越来越来严 重, 灾害的发生频率在未来的若干年内将增加, 
影响的范围也会越来越广泛[1]。《第三次气候 变化国家评估报告》指出: 未来我国极端事件 增加，暴雨、强风暴潮、大范围干旱等发生的 频次和强度增加, 洪涝灾害的强度呈上升趋势 [2]。我国是农业大国, 粮食产量在我国国民生 产总值中占有举足轻重的地位。同时, 由于我 国在世界经济生活中越来越明显主导地位, 中 国粮食安全不仅影响到我国的发展, 而且会影 响到世界的政治和经济格局。由于全球气候的 变化以及我国所处的特殊地理环境, 造成我国 农业灾害频发[3], 据统计, 1972-2013 年我国 平均受灾面积为 $4.39 \times 10^{5} \mathrm{~km}^{2} / \mathrm{a}$, 其中洪涝灾 害受灾面积为 $1.05 \times 10^{5} \mathrm{~km}^{2} / \mathrm{a}$, 占气象灾害受 灾面积的 $24.08 \%$, 是仅次于旱灾造成严重损 失的气象灾害。玉米是我国主要的粮食作物, 玉米种植面积年均在 $2.3 \times 10^{7} \mathrm{hm}^{2}$ 以上, 年均 总产量约为 $1.2 \times 10^{11} \mathrm{~kg}$ 左右, 面积与总产分别 占我国粮食作物的 $21 \%$ 和 $24 \%$, 是我国三大 粮食作物之一。其中吉林省中西部地区位于我 国黄金玉米带上, 同时该区也是是吉林省乃至 东北地区典型的洪涝灾害频发地区[4]。对该区 进行玉米涝灾脆弱性曲线的研究, 对于提高我 国的农业气象灾害的研究水平和应急管理能 力、实现科学抗灾和主动抗灾的目标具有重要 意义。其研究成果可推广到我国其它农业地区, 为玉米生产合理布局及防灾避灾提供科学依 据和方法

目前关于农业洪涝灾害脆弱性曲线研究 大多集中于对不同致灾强度下某一类农作物 的受涝损失率的研究 [5]。致灾因子指标通常选 取水深和淹没时间, 损失程度则一般用减产率、 作物死亡率表示。基于灾情数据进行脆弱性分 析是最常见的方法之一。主要是通过查阅历史 文献、灾情数据库、实地调查等, 将致灾因子 与成灾指标建立一一对应的关系, 然后利用回 归模型、神经网络等方法探究两者之间的关系 [6]。基于对承灾体价值调查和受灾情景假设, 推测出不同致灾强度下的损失率进而构建脆 弱性曲线的方法, 被称为系统调查法。主要是 判断不同水位情景下农作物的淹没深度, 最后 建立农作物脆弱性曲线 $[7,8]$ 。作物模型着重对 作物生长发育过程及其与环境的关系进行定 量描述和预测, 可在一定程度上定量分析不利 气象条件作物生长发育和产量形成的影响, 并 已在农业气象灾害分析中得到初步应用 $[9,10]$ 。 在农业洪涝脆弱性方面也进行了一系列的尝 试, 例如, Velde M,et al.利用 EPIC 模型分析 了法国 2007 年多雨条件下小麦和玉米的产量 情况[11]。杨京平和陈杰试图利用计算机模拟
渍水时期及持续时间对春玉米生长及产量的 影响[12]。基于模型模拟构建的脆弱性曲线的 优点在于: 可以模拟任意致灾强度中的农作物 脆弱性水平, 并且可以从灾害自身机理和农作 物生长机理出发详细描述农作物的脆弱性[13]。 因此, 本研究拟选取吉林中西部玉米主产区为 研究示范区, 以玉米不同发育阶段为切入点, 从玉米脆弱性出发, 基于 $5 \mathrm{~km} \times 5 \mathrm{~km}$ 尺度的格 网数据, 利用 CERES-Maize 模型模拟吉林中 西部地区典型玉米品种 (郑单 958) 的脆弱性 曲线, 估算不同致灾强度可能造成的玉米生长 过程中关键生理指标的损失, 为科学制定应急 抗灾、减灾措施提供理论依据和技术支撑。

\section{2. 材料与方法}

\section{1. 研究区概况}

吉林省中西部地区位于吉林省松嫩平原 的西南端、科尔泌草原的东部, 西毗邻内蒙古 自治区, 北靠黑龙江省(图 1), 地理范围介于 北纬 $43^{\circ} 16^{\prime} \sim 46^{\circ} 18^{\prime}$, 东经 $12^{\circ} 38^{\prime} \sim 127^{\circ} 45^{\prime}$, 包 括白城、松原、四平、长春和吉林 5 个地区 20 个市县(区)。白城市: 镇类县、洮南市、通 榆县、大安市; 松原市: 扶余县、前郭尔罗斯 蒙古族自治县、乾安县、长岭县; 长春市: 榆 树市、德惠市、农安县、双阳区; 四平市: 公 主岭、双辽县、梨树县; 吉林市: 舒兰市。研 究区域总面积 828.73 万公顷, 占吉林省土地 面积的 $44.23 \%$ 。

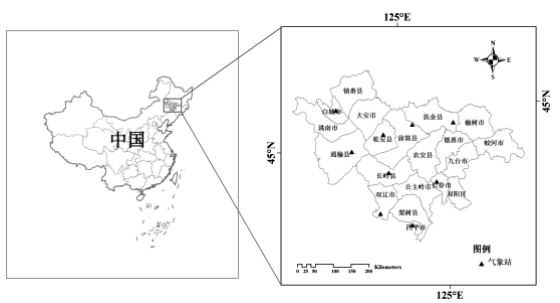

图 1 吉林中西部地区示意图

对于吉林省整个省份来说, 该地区的气候 类型为温带大陆性季风气候, 但是由于吉林省 西北部平原区临近蒙古高原, 使得吉林省中西 部地区变为温带半湿润-半干旱气候区。气候 特点为四季分明, 春季多风少雨、冬季漫长而 寒冷, 夏季多雨、秋季温差较大, 年蒸发量在 $700-1300 \mathrm{~mm}$ 之间, 日照时数 $2600-3000 \mathrm{~h}, 10^{\circ} \mathrm{C}$ 
Risk Analysis and Crisis Response in Big Data Era (RAC-16)

以上的积温为 $2800-3000{ }^{\circ} \mathrm{C}$, 无霜期在 $120-160$ 天, 其中吉林省中部地区主要受大陆季风气候 的影响, 而西部地区则由于受蒙古高压的汼制, 造成研究区的降水量在时空上呈现分布不均 的态势, 最终造成水资源匹配组合在空间分布 上存在着较大的“错位现象” , 具体表现为年 降水量在 200-650mm 之间, 且降水量主要集 中于 6-8 月份, 占全年降水量的 $60 \%$ 以上, 多 集中在作物生长旺盛的季节, 降水量从东南部 向西北内陆递减。

\section{2. 研究方法}

玉米是一种需水量很大的农作物, 并且不 同生育期对于水分的需求不同，因此降水量的 多少显著影响玉米作物的生长, 通过对以往文 献进行梳理发现, 国内外学者在对涝灾危险性 评价的研究中, 对于涝灾致灾强度的确定, 大 部分用单一的指标进行表征, 如利用 $\mathrm{Z}$ 指数, SPI 指数的大小或者根据干早划分标准确定的 不同干旱等级的频率, 极端降水量或者淹没水 深。但是对于玉米作物来说, 极端降水引起的 涝灾及对玉米生长造成的影响, 不仅与 SPI 值 确定的雨涝等级的频率有关, 而且与不同生育 期内雨涝历时有关。因此本文根据雨涝等级划 分标准对吉林省中西部地区进行雨涝强度和
雨涝历时的划分。然后利用 Copula 函数计算 致灾强度指数, Copula 函数具有无需统一变 量边缘分布的优势, 已经被广泛应用于灾害及 风险评价领域 [14-16]。本研究主要是利用 Copula 函数对雨涝强度和雨涝历时进行二维 联合分布的计算, 致灾强度指数的计算如公式 (1) 所示:

$$
\mathrm{H}_{w}=\mathrm{C}\left(\mathrm{w}_{i}, \mathrm{w}_{d}\right)
$$

其中 $\mathrm{H}_{w}$ 为致灾强度指数, $w_{i}$ 为周 $\mathrm{SPI}$ 指数确定 的致灾强度, $w_{d}$ 为周 SPI 指数确定的致灾强度 历时, 不同站点的 $\mathrm{H}_{w}$ 值由各站点的致灾强度 和致灾强度历时确定的 Copula 函数进行计算。 其中 SPI 为标准化降水指数的简称, SPI 通过 计算给定时间尺度内降雨量的累积概率，能 够在多个时间尺度上进行计算比较，不仅可反 映短时间内降雨量的变化, 如对农业生产有重 要影响的土壤水分的动态变化, 也可以反映长 期水资源的演变情况, 如地下水供给、地表径 流等。

\section{3. 数据库的建立}

根据 CERES-Maize 模型的需要, 本研究收 集并整理了一系列的基础数据库来进行吉林 中西部地区玉米涝灾脆弱性曲线的构建, 具体 数据见表 1 。 表 1 基础数据库列表

\begin{tabular}{|c|c|c|c|}
\hline 数据库名称 & 数据内容 & 数据来源 & 数据年份 \\
\hline $\begin{array}{c}\text { 地面气象观测数 } \\
\text { 据库 }\end{array}$ & $\begin{array}{c}\text { 吉林省中西部地区 } 14 \text { 个气象站点逐日数 } \\
\text { 据, 包括降水量、最高气温、最低气温、 } \\
\text { 日照时数 }\end{array}$ & $\begin{array}{c}\text { 中国国家气象局信 } \\
\text { 息中心 }\end{array}$ & $1960-2014$ \\
\hline 中国土地利用图 & $\begin{array}{c}1: 100 \text { 万土地利用数据, 包括水田、旱 } \\
\text { 地、草地、林地等 }\end{array}$ & 中国科学院 & 2000 \\
\hline $\begin{array}{c}\text { 土壤理化属性数 } \\
\text { 据库 }\end{array}$ & $\begin{array}{c}\text { 包括土层分布、机械组成和有机碳含量 } \\
\text { 等 }\end{array}$ & $\begin{array}{c}\text { 国际粮食政策研究 } \\
\text { 所 } \\
\text { 《吉林土壤》 }\end{array}$ & 2009 \\
\hline $\begin{array}{c}\text { 农作物田间观测 } \\
\text { 数据库 }\end{array}$ & $\begin{array}{c}\text { 《东北地区玉米研究站点资料》的吉林 } \\
\text { 省部分 }\end{array}$ & $\begin{array}{l}\text { 国家气象信息中心 } \\
\text { 资料室 }\end{array}$ & $1980-2014$ \\
\hline $\begin{array}{l}\text { 吉林中西部分县 } \\
\text { 统计农业数据库 }\end{array}$ & 各市、县玉米产量、化肥施用量等 & $\begin{array}{l}\text { 《吉林省统计年 } \\
\text { 鉴》 }\end{array}$ & $1985-2014$ \\
\hline
\end{tabular}

\section{3. 玉米港灾脆弱性曲线的构建过程}

\section{1. 脆弱性曲线的构建}

根据研究表明, 苗期长期的阴雨天气, 低温寡照 常常导致温度偏低偏低, 不利于植株正常生长, 植株 矮小。因此出苗-拔节期选择叶面积指数 (LAI) 作为
损失指标; 进入拔节期, 频繁降雨天气会导致杂草快 速生长, 杂草与植株争抢营养, 致使部分植株出现营 养不良的情况, 影响作物的生长, 因此拔节一抽雄期 选择 LAI 作为损失指标; 抽雄一乳熟期, 大量降水 导致正常光合作用受到影响, 阻碍干物质的形成, 导 致后期玉米籽粒不饱满。因此选取粒重作为损失指 标; 乳熟一成熟期, 过量降水导致不能正常光合作用, 
Risk Analysis and Crisis Response in Big Data Era (RAC-16)

由于灌浆不充分, 收获的新作容重降低, 因此这一时 期选择粒重作为损失指标。

根据 CERES-Maize 模型的特点, 先控制模型运 行过程中氮胁迫、养分胁迫和病虫害胁迫等, 然后设 定为完全满足养分与完全满足水分 ( $S_{1}$ 情景) 与完全 满足养分与雨养 ( $S_{2}$ 情景), 可认为是达到了排除温 度胁迫对作物生长的影响, 即 $\mathrm{S}_{1}$ 情景下与 $\mathrm{S}_{2}$ 情景下 不同生育期相应指标的损失率为受涝渍扰动的敏感 程度。损失率的计算方法为: 利用每个网格 $\mathrm{S}_{1}$ 情景 下某一生育期某一指标的数值减去 $\mathrm{S}_{2}$ 情景下相应的 数值作为受港渍胁迫影响的损失值, 该值与该网格 $\mathrm{S}_{1}$ 情景下数值的比作为相应指标的损失程度, 计算如 公式 (2) 所示:

$$
S=\frac{Y_{1-} Y_{2}}{Y_{1}}
$$

式中: $S$ 为某一网格某一生育期某一敏感性指标 因涝损失程度, $Y_{1}$ 和 $Y_{2}$ 分别为 $S_{1}$ 和 $S_{2}$ 情景下的某 一指标的数值。

\subsection{CERES-Maize 模型的校验}

用于 CERES-Maize 模型校验的数据有: (1)模型 的相关数据: (作物遗传参数、耕作参数、施肥信息); (2)基本输入数据: 逐日气象网格数据集、土壤数据、 田间管理数据（播种、农药、施肥和物候期等）等。 灌溉方式设定为自动灌溉。进行作物遗传参数的本地 化。具体的方法是: 按照模型所需要的数据, 将洮 南市试验点 2008-2014 年的日气象数据、土壤数据 和这 5 年的田间管理数据输入设置好的站点 CERES-Maize 模型中, 将输出的作物产量和实际测 得的作物产量进行拟合。通过反复运行模型, 运用遗 传算法调整主要参数值, 直到模拟的产量与实测值在 趋势上比较一致, 而且数值也比较接近 (图 2), 最后 拟合的平均误差为 0.093 。基于校验好的遗传参数和 已有的基本输入数据, 对研究区 9 个农业气象站点 2010 年的统计产量数据和模型模拟的产量进行对比 验证 (图 3), $\mathrm{R}^{2}$ 相关系数为 0.5305 , 说明空间上的 校验结果较为合理。

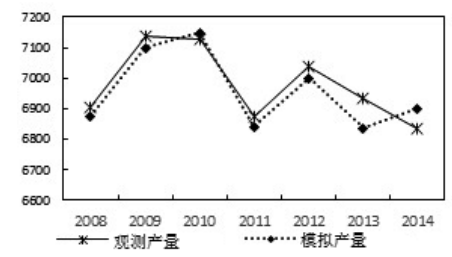

图 2 CERES-Maize 模型的参数校验图

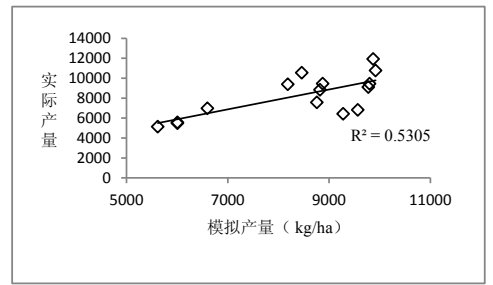

图 3 CERES-Maize 模型的空间尺度校验图

\section{3. 结果与分析}

郑单 958 是辽宁省、吉林省等 7 省区及国家农 作物品种审定委员会审定的玉米品种, 在东北春播玉 米区平均全生育期为 $146 \mathrm{~d}$, 是近年来东北地区主要 种植的品种之一, 因此选取典型玉米品种郑单 958 作为 CERES-Maize 模型所需输入的玉米遗传参数, $\mathrm{S}_{1}$ 情境下, 利用 1960-2012 年平均逐日气象网格数据, 对研究区 $5 \mathrm{~km} \times 5 \mathrm{~km}$ 网格单元玉米生长过程进行模 拟, $S_{2}$ 情境下, 通过 CERES-Maize 模型模拟研究区 $5 \mathrm{~km} \times 5 \mathrm{~km}$ 网格上 1985 年、1994 年、2005 年和 2010 年等典型涝灾年份里玉米的生长过程。并且提取每个 生育阶段受涝渍胁迫影响的损失指标, 计算出每个生 育期内不同致灾强度指数, 结合自然脆弱性曲线的定 义, 计算出吉林省中西部地区玉米不同生育期内涝灾 脆弱性曲线图 (4)。玉米的出苗一拔节期、拔节 抽雄期、抽雄一乳熟期、乳熟一成熟期的关系式分别 为 $y_{1} 、 y_{2} 、 y_{3} 、 y_{4}$ 。

$$
\begin{aligned}
& y_{1}=0.3328 x^{2}+0.1467 x+0.1698, \mathrm{R}^{2}=0.8763 \\
& y_{2}=4.0722 x^{3}-5.3751 x^{2}+2.4333 x-0.0028, \mathrm{R}^{2}
\end{aligned}
$$
$=0.5551$

$$
\begin{aligned}
& y_{3}=-0.0081 x^{2}+0.147 x+0.0924, \mathrm{R}^{2}=0.6677 \quad(5) \\
& y_{4}=-0.2095 x^{2}+0.3756 x+0.041, \mathrm{R}^{2}=0.3591 \quad(6)
\end{aligned}
$$

其中出苗-拔节期、拔节-抽雄期、抽雄-乳熟期的 脆弱性皆通过了 0.05 的F值检验, 也就是说, 随着致 灾强度指数的增加, 每个生育期内对应指标的损失 率增长趋势显著。其中出苗一拔节期受灾最为敏感, 降水量显著影响玉米叶片的生长, 损失率最高可达 $60 \%$ 以上, 拔节一抽雄期, 由于需水量较大, 当致灾强 度指数大于 0.5 时, 损失率不再增加。抽雄-乳熟期, 粒重损失率可高达 $25 \%$ 。乳熟一成熟期, 虽然随着致 灾强度指数的增加, 粒重损失率呈线性增长趋势, 但是增长趋势不明显, 主要与吉林省中西部地区年内 降水分布有关, 降水量主要集中在7-8月, 进入9月之 后, 降水量显著减少, 对玉米干物重积累的影响逐渐 减弱。综上所述, 吉林省中西部地区玉米涝灾脆弱性 最强的时期为出苗-拔节期, 其次为拔节-抽雄期和抽 雄-乳熟期, 乳熟-成熟期受灾较轻。 
Risk Analysis and Crisis Response in Big Data Era (RAC-16)
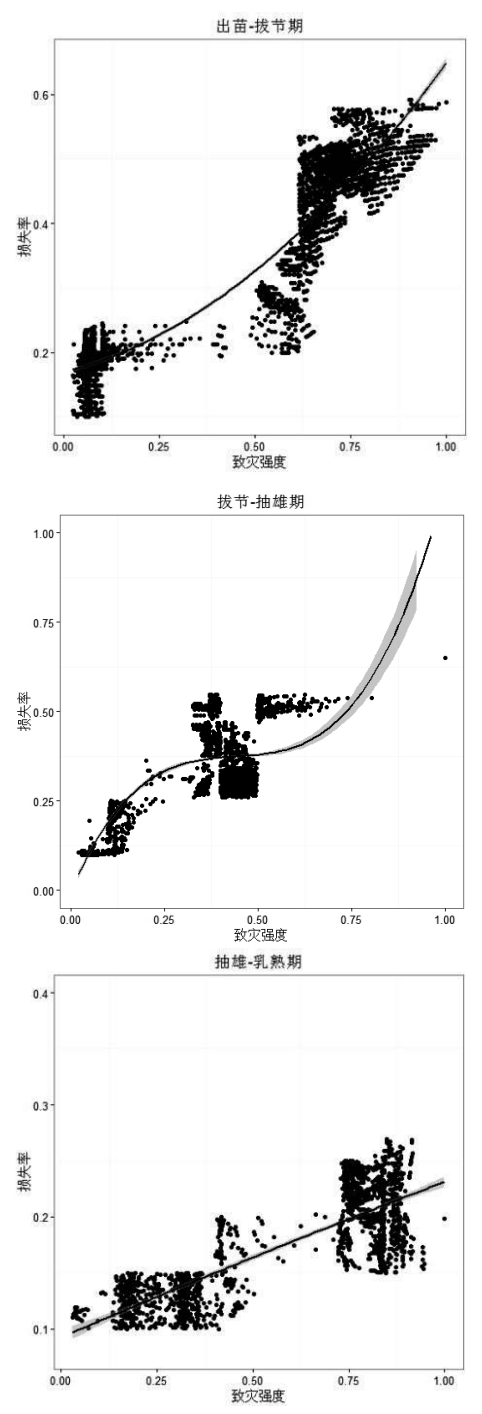

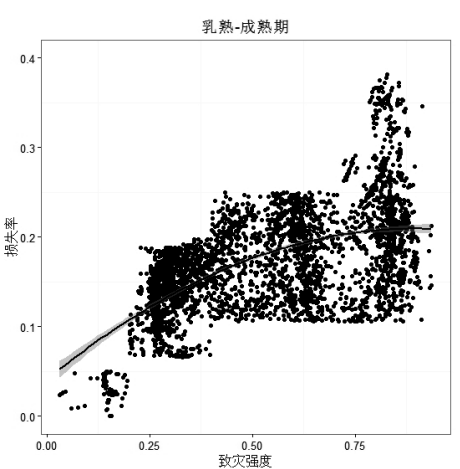

图 4 吉林中西部地区不同生育期玉米涝灾脆弱性曲 线

4. 结论

脆弱性曲线是脆弱性评价与自然灾害风险评价 研究的桥梁与纽带, 如何建立有效的玉米涝灾脆弱性 曲线是评估玉米受涝损失的关键, 本研究通过选取对 涝灾较为敏感的玉米生理参数作为损失指标, 通过对 典型涝灾年份的玉米逐日生长过程进行模拟, 并且通 过站点观测数据对模型空间化结果进行检验, 最终在 计算典型涝灾年份不同生育期致灾强度指数的基础 上, 建立不同生育期不同损失指标的玉米涝灾脆弱性 曲线。吉林省中西部地区玉米涝灾脆弱性由大到小依 次为: 出苗一拔节期、拔节一抽雄期、抽雄一乳熟期、 乳熟一成熟期, 本研究突破了传统建立脆弱性曲线过 程中选取产量损失作为玉米涝灾脆弱性指标的限制, 通过构建不同生育阶段相对应的受涝敏感性较高的 生理参数作为损失指标, 建立了全生育期的玉米涝灾 脆弱性曲线, 此结论可以作为减轻涝灾对于玉米生长 的影响, 选择合理的灌溉时期和排水设施提供重要依 据, 以达到最优玉米产量的结果。

本研究在对吉林省中西部地区构建玉米涝灾脆 弱性曲线的过程中, 由于玉米品种参数选择的限制, 只进行了郑单 958 这单一玉米品种的自然脆弱性曲 线的构建, 对于不同玉米品种在该研究区的时空差异 性表现的研究上存在着一定的不足, 需要对玉米品种 的相关数据进行进一步的收集整理, 以完善玉米涝灾 脆弱性曲线构建的研究。

\section{Acknowledgements}

This study was supported by the National Key Technology R\&D Program of China under Grant 
Risk Analysis and Crisis Response in Big Data Era (RAC-16)

(No.2013BAK05B01), the National Natural Science Foundation of China under Grant (No. 41571491) and China Special Fund for Meteorological Research in the Public Interest (No. 2015001) and the National Non-Profit Research Program of China (No.201401015).

\section{致谢}

本研究得到“十二五”社发领域国家科技支撑计划 课题（2013BAK05B01），国家自然科学基金项目 (41571491)和公益性行业(气象)科研专项(2015001) 和水利部公益性行业科研专项经费项目 (201401015) 资助。

\section{参考文献}

[1] Zhang Q, Zhang J, Wang C. Risk assessment of drought disaster in typical area of corn cultivation in China. Theoretical and Applied Climatology, 2016.

[2] 编写委员会编著第三次气候变化国家评估报告. 第三次气候变化国家评估报告. 北京: 科学出版 社, 2015.

[3] 王春乙, 张继权, 霍治国, 等. 农业气象灾害风 险评估研究进展与展望. 气象学报,73 (1):1-19, 2015.

[4] 秦元明. 中国气象灾害大典・吉林卷. 北京: 气象 出版社, 2008.

[5] 蒋尚明，王友贞，汤广民，等. 淮北平原主要农 作物涝渍灾害损失评估研究. 水利水电技术, 42(8):63-67, 2011.

[6] Chau V N, Holland J, Cassells S, et al. Using GIS to map impacts upon agriculture from extreme floods in Vietnam. Applied Geography, 41:65-74, 2013

[7] Wang H, Kuo P, Shiau J. Assessment of climate change impacts on flooding vulnerability for lowland management in southwestern Taiwan. Natural Hazards, 68(2):1001-1019, 2013.

[8] McFadyen L, Grieve A M. Effects of irrigation management and watertable depth on growth and yield of field-grown Sultana grapevines in south eastern Australia. Agricultural Water Management, 111(0):20-26, 2012.

[9] Velde M, Tubiello F, Vrieling A, et al. Impacts of extreme weather on wheat and maize in France: evaluating regional crop simulations against observed data. Climatic Change, 113(3-4):751-765, 2012.

[10] Jia H, Wang J, Cao C, et al. Maize drought disaster risk assessment of China based on EPIC model. International Journal of Digital Earth, 5(6):488-515, 2011

[11] Velde M, Tubiello F, Vrieling A, et al. Impacts of extreme weather on wheat and maize in France: evaluating regional crop simulations against observed data. Climatic Change, 113(3-4):751-765, 2012.

[12] 杨京平，陈杰. 计算机模拟渍水时期及持续时间 对春玉米生长及产量的影响. 生物数学学报, 16(3):253-261, 2001.

[13] 郭恩亮, 张继权, 孙仲益, 等. 农业洪涝灾害风 险评价研究综述：中国灾害防御协会风险分析 专业委员会第六届年会，中国内蒙古呼和浩特, 2014.

[14] 郭恩亮, 周沫, 张继权, 等. 基于Copula函数的 长春市暴雨联合分布与特征分析. 灾害学, 30(4):173-177, 2015.

[15] Tiwari N, Singh S B. Analysis of a Risky Two Unit System under Marked Process Incorporating Two Repairmen with Vacations. The Journal of Risk Analysis and Crisis Response, 5(4):200-214, 2015.

[16] Liu D, Wang D, Wang Y. Eutrophication Hazard Evaluation Using Copula-Cloud. The Journal of Risk Analysis and Crisis Response, 6(1):10-14, 2016. 